\title{
Heart disease and subtle ECG findings: A case of Wellens' syndrome
}

\author{
Elizabeth Dobben, Sherene Lattimore and Julie L. Welch
}

A 66-year female presented to the emergency department with a 2-h history of substernal chest pain, nausea, and diaphoresis. Initial treatment included aspirin and nitroglycerin, with improvement of pain. Pertinent physical examination findings included a heart rate of $60 \mathrm{bpm}$, blood pressure of 132/58 mmHg, and oxygen sats of $97 \%$ on room air. Serial ECGs demonstrated normal sinus rhythm with progressively deepening biphasic T-waves in precordial leads V2-V4 consistent with Wellen's syndrome (Fig. 1 , Fig. 2 ). Laboratory evaluation was remarkable for an elevated troponin. Chest X-ray was normal. Interventional cardiology was urgently consulted for cardiac catheterization, which revealed 95\% stenosis of her proximal left anterior descending coronary artery, with subsequent placement of a drug-eluding stent. She had an uneventful recovery and was discharged to home. At 1 and 5 month cardiology follow up she had preserved cardiac function and resolution of the ECG findings.

\section{Appendix A. Supporting information}

Supplementary data associated with this article can be found at doi:10.1016/j.visj.2017.07.008.

\section{Further Reading}

1. Hollenberg SM. "Myocardial Ischemia" Principles of Critical Care. 4e eds.; 25 February 2017.

2. Ritchie JV. "ECG Abnormalities" The Atlas of Emergency Medicine. 4e eds.; 25 February 2017.

3. Wilson PM. Overview of the Risk Equivalents and Established Risk Factors for Cardiovascular Disease; 3 March 2017.

This is the author's manuscript of the article published in final edited form as:

Dobben, E., Lattimore, S., \& Welch, J. L. (2017). Heart disease and subtle ECG findings: A case of Wellens’ syndrome. Visual Journal of Emergency Medicine, 9, 47-48. https://doi.org/10.1016/j.visj.2017.07.008 


\section{Figures}

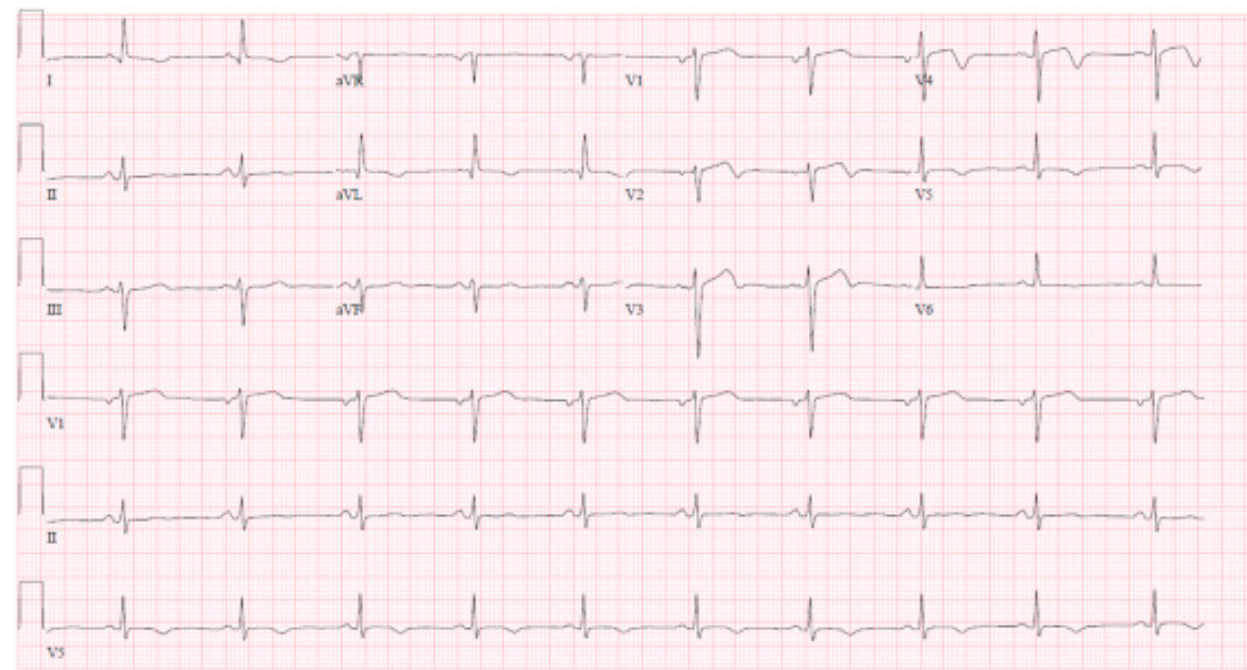

Fig. 1

First EKG preformed: Biphasic T-waves in V2-V4 with inverted T-waves.

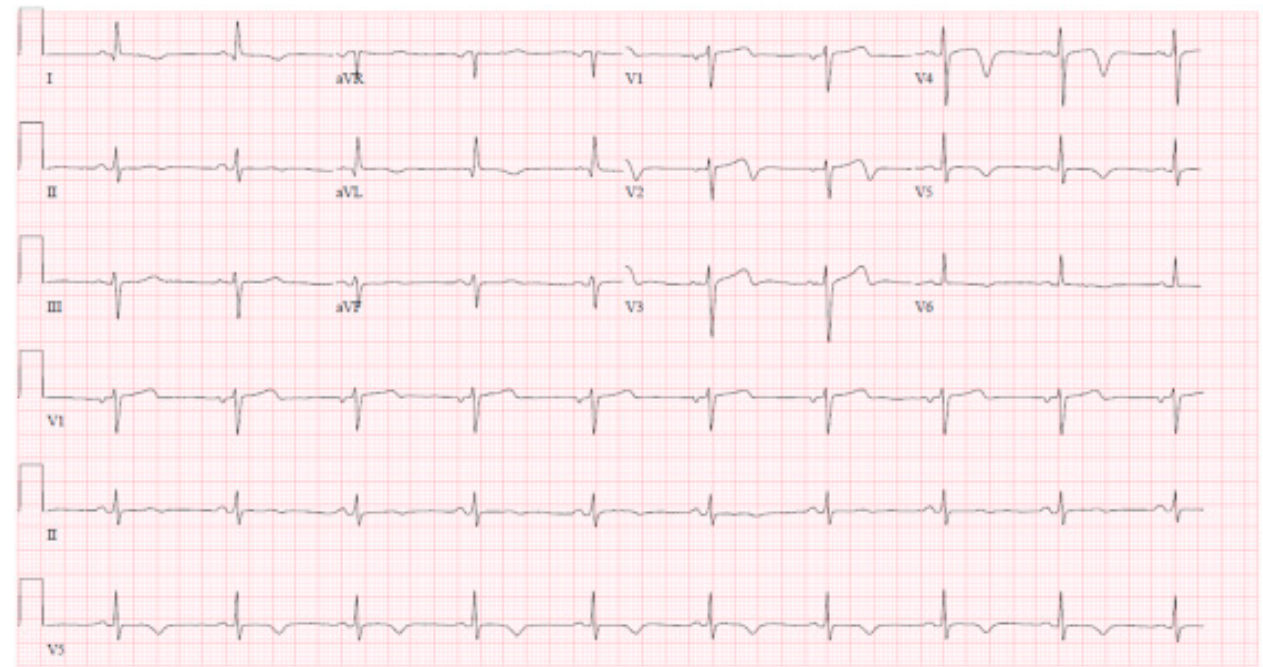

Fig. 2

Second EKG preformed; Worsening Biphasic T-waves in V2-V4 with inverted T-waves. 